\title{
Long-term Control of Plasma Calcitriol Concentration in Dogs and Humans Dominant Role of Plasma Calcium Concentration in Experimental Hyperparathyroidism
}

\author{
Henry N. Hulter, Bernard P. Halloran, Robert D. Toto, and John C. Peterson \\ Renal Laboratory, United States Public Health Service Hospital and Department of Medicine, University of California, San Francisco, \\ California 94143; and Renal Laboratory, Veterans Administration Medical Center and Department of Medicine, \\ University of Florida, Gainesville, Florida 32602
}

\section{Abstract}

Despite great interest in the elevated circulating levels of calcitriol $\left(1,25-[\mathrm{OH}]_{2} \mathrm{D}\right)$ associated with the clinical syndrome of human primary hyperparathyroidism, the relative potencies of known and potential stimuli/suppressors of long-term calcitriol levels have not been evaluated in either clinical or experimentally induced hyperparathyroid states. Based on reports that aparathyroid animals exhibit suppressed plasma calcitriol concentration and that acute administration of parathyroid hormone (PTH) to both humans and experimental animals or to renal slices in vitro results in increased plasma calcitriol concentration/production rate, it might be predicted that a chronic experimental model of either hypercalcemic primary hyperparathyroidism or hypocalcemic secondary hyperparathyroidism would show increased plasma calcitriol concentration. Chronic alterations in plasma calcium concentration have not been implicated as modulating calcitriol levels in any species. Accordingly, we investigated the long-term response of plasma calcitriol concentration in states of sustained experimental primary and secondary hyperparathyroidism. Intact dogs (group I) undergoing continuous intravenous PTH infusion for $12 \mathrm{~d}$ developed sustained hypercalcemia and hypophosphatemia, and plasma calcitriol concentration decreased from $23 \pm 3$ to $14 \pm 3 \mathrm{pg} / \mathrm{ml}(P<0.01)$. Subsequent chelator (EGTA)induced chronic normalization of hypercalcemia during ongoing PTH infusion resulted in a large and sustained increase in plasma calcitriol concentration to supernormal levels, reversible during subsequent cessation of chelator infusion. In additional intact dogs (group II), chronic chelator-induced hypocalcemic secondary hyperparathyroidism resulted in a sustained increase in plasma calcitriol concentration despite hyperphosphatemia. In normal human subjects undergoing a 12-13-d continuous intravenous PTH infusion to result in sustained moderate hypercalcemia $(12.0 \pm 0.2 \mathrm{mg} / 100 \mathrm{ml})$ and hypophosphatemia, plasma calcitriol concentration decreased significantly $(P<0.01)$ as in group I dogs and was followed by reversal to normal levels in a recovery period. The present results provide strong evidence in both humans and dogs that during experimentally induced chronic PTH excess, alterations in plasma calcium concentration dictate the directional response of circulating

Address reprint requests to Dr. Hulter, Division of Nephrology, 1065 HSE, University of California, San Francisco, CA 94143.

Received for publication 28 September 1984.

J. Clin. Invest.

(C) The American Society for Clinical Investigation, Inc.

$0021-9738 / 85 / 08 / 0695 / 08 \quad \$ 1.00$

Volume 76, August 1985, 695-702 calcitriol concentrations. The long-term potency of plasma calcium concentration as a modulator of calcitriol metabolism is sufficient to override opposing modulation by plasma phosphorus concentration and PTH.

\section{Introduction}

A wide variety of experimental evidence in both humans and laboratory animals indicates that the renal mitochondrial metabolite, calcitriol, is the most potent known circulating metabolite of vitamin $\mathrm{D}$ and that physiological variation in plasma calcitriol concentration can account, in large part, for the known effects of vitamin $D$ on mineral metabolism in bone, intestine, and extracellular fluid (ECF) $(1,2)$. However, the identities and relative potencies of the individual factors that regulate the steady-state plasma concentration of calcitriol are still unclear. Postulated stimuli for calcitriol production include chronic dietary calcium restriction (3-8), acute administration of parathyroid hormone (PTH) (8-11), and chronic hypophosphatemia $(4,12-15)$. Recently, it has been reported that in calves and goats, acute hypercalcemia, per se, can suppress plasma calcitriol concentration despite the continued presence of high circulating PTH levels (16).

Clinical states of chronically deranged calcium metabolism typically provide a difficult setting for interpretation of plasma calcitriol concentration inasmuch as clinical circumstances often dictate potentially conflicting signals to calcitriol production (e.g., PTH excess vs. hypercalcemia in primary hyperparathyroidism). Studies investigating the chronic steady-state regulation of plasma calcitriol concentration in response to prolonged, independent (and potentially conflicting signal) alterations in plasma calcium, PTH, and phosphorus concentrations have not been reported in any species.

To investigate the chronic regulation of plasma calcitriol concentration, we have assessed the relative potency of potential conflicting signals by performing experiments in dogs and humans in which plasma calcium concentration is maintained, at chronically increased or decreased levels in the presence of either increased or absent PTH levels and with control of plasma phosphate concentration. The results of these studies indicate that as long as minimal (albeit suppressed) PTH is present in both dogs and humans, the long-term magnitude of plasma calcium concentration, over a wide range of values, is a more potent regulator of plasma calcitriol concentration than is PTH.

1. Abbreviations used in this paper: $1 \alpha$-hydroxylase, 25 -hydroxyvitamin D- $1 \alpha$-hydroxylase; bPTH, bovine parathyroid hormone; ECF, extracellular fluid; PTH, parathyroid hormone; TPTX, thyroparathyroidectomized. 


\section{Methods}

\section{Studies in dogs}

The chronic effects of PTH-excess and calcium-excess states on plasma and urinary mineral composition and vitamin $\mathrm{D}$ metabolism were determined in 12 female mongrel dogs weighing 10-22 kg. Throughout the studies the dogs were fed a constant amount $(30 \mathrm{~g} / \mathrm{kg}$ per d) of a low electrolyte synthetic diet (4.2 mg calcium per $100 \mathrm{~g})$, (17) homogenized with distilled water $(60 \mathrm{ml} / \mathrm{kg})$, and supplemented with specified amounts of sodium, potassium, and calcium as the chloride or neutral phosphate salts. After the establishment of a steady state of plasma and urinary electrolyte composition (control period), chronic hyperparathyroidism or hypercalcemia was induced for a 7-12 d experimental period. Control period observations were of 3-12 d duration and followed a prefeeding period of 2-9 d during which the dogs adjusted to the experimental protocol. Dogs that failed to eat spontaneously were tube-fed. Studies were terminated if vomiting resulted in a cumulative loss $>100 \mathrm{ml}$. At 9 a.m., arterial blood samples from fasting dogs were obtained percutaneously in heparinized glass syringes from the femoral artery at 24-72 h intervals. Urine was collected from the animals in metabolic cages over stainless steel surfaces into glass bottles containing mineral oil and thymol-chloroform preservative. Values for urinary excretion and clearance data are reported as normalized to $20 \mathrm{~kg}$ body wt.

Group I: effect of chronic intravenous infusion of bPTH on mineral and vitamin $D$ metabolism in intact dogs $(n=5)$. The objective of this protocol was to investigate the chronic steady-state plasma calcitriol response to the induction of a model of primary hyperparathyroidism characterized by continuous and persistent (12-13 d) infusion of a super-physiological dose of bovine parathyroid extract (bPTH; Lilly, Eli, \& Co., Indianapolis, IN). Accordingly, dogs were fitted with a chronic indwelling external jugular vein catheter for chronic intravenous infusion of bPTH (18). After a stable control period during which vehicle alone (porcine gelatin, 250 bloom, Dynagel Inc., Calumet City, IL, in $0.225 \% \mathrm{NaCl}$ and $0.1 \%$ benzyl alcohol) was infused, an infusion of bPTH in vehicle was substituted to produce sustained hypercalcemia. Electrolyte supplements to the diet consisted of $\mathrm{Ca}^{++} 3.0 \mathrm{meq} / \mathrm{kg}$ as the $\mathrm{Cl}^{-}$salt, $\mathrm{Na}^{+} 3.0 \mathrm{meq} / \mathrm{kg}$, and $\mathrm{K}^{+} 3.0 \mathrm{meq} / \mathrm{kg}$ as the neutral phosphate salts daily during all periods of study. Infectious complications of chronic intravascular catheterization were prevented by oral administration of trimethoprim $80 \mathrm{mg} /$ sulfamathoxazole $400 \mathrm{mg}$ (Burroughs Wellcome and Co., Research Triangle Park, NC) twice daily. The dietary water content was increased by $50 \mathrm{ml} / \mathrm{kg}$ per $\mathrm{d}$ either throughout control and PTH periods or on days 5 or 6 of PTH infusion to prevent development of hypernatremia observed in pilot studies in which water intake was not supplemented. In one dog of group I, after $13 \mathrm{~d}$ of PTH infusion, hypercalcemia was corrected by superimposition of a second infusion of $\mathrm{Na}_{4}$ EGTA ( $3.0 \mathrm{mmol} / \mathrm{kg}$ daily) for five additional days as described in detail for group II. $\mathrm{CaNa}_{2}$ EGTA was substituted for equimolar $\mathrm{Na}_{4}$ EGTA for one additional day.

Group II: effect of chronic intravenous infusion of the tetrasodium salt of EGTA $\left(\mathrm{Na}_{4} \mathrm{EGTA}\right)$ in intact dogs $(n=4)$. A model of chronic secondary hyperparathyroidism was devised for the purpose of assessing the effects of a continuous elevation of endogenous PTH levels on calcitriol metabolism in the absence of attendant hypercalcemia present in group I. Accordingly, animals were fitted with a chronic indwelling external jugular vein catheter for chronic infusion of the $\mathrm{Ca}^{++}$chelator EGTA (Sigma Chemical Co., St. Louis, MO). During prefeeding and control periods, EGTA was administered by continuous intravenous infusion in a nonchelating form $\left(\mathrm{CaNa}_{2}\right.$ EGTA), $3 \mathrm{mmol} / \mathrm{kg}$ per d. After a 4-5-d period of stable control observations, the intravenous solution was changed to equimolar delivery of the active chelating form of EGTA $\left(\mathrm{Na}_{4}\right.$ EGTA) and was continued for a 7-d period. This rate of active EGTA infusion is known to result in a marked increase in plasma PTH levels in dogs (19). Water intake was increased by 50 $\mathrm{ml} / \mathrm{kg}$ on the fourth day of $\mathrm{Na}_{4}$ EGTA administration to prevent hypernatremia. Electrolyte supplements to the synthetic diet and antibiotic administration were identical to those in group $I$.

Group III: effect of chronic hypercalcemia induced by the substitution of continuous intravenously administered calcium chloride for equivalent sodium chloride to thyroparathyroidectomized (TPTX) dogs $(n=3)$. The objective of this protocol was to characterize the effect of prolonged hypercalcemia on calcitriol metabolism under conditions in which PTH was absent from the circulation. Accordingly, TPTX dogs were fitted with chronic indwelling external jugular vein catheters for chronic, continuous infusion of electrolytes as in groups I and II. TPTX was performed at least 1 wk before control observations. The adequacy of parathyroidectomy was ensured by acceptance of animals for study only if plasma total calcium concentration decreased postoperatively by at least $2.0 \mathrm{mg} / 100 \mathrm{ml}$. After surgery and throughout the period of study, the animals were maintained on oral sodium levothyroxine, $10 \mu \mathrm{g} / \mathrm{kg}$ twice daily (Armour Pharmaceutical Co., Tarrytown, NY), a dosage reported to result in a euthyroid state in dogs (20). After catheter placement, an infusion of $\mathrm{Ca}^{++} 0.5-1.0 \mathrm{meq} /$ $\mathrm{kg}$ per $\mathrm{d}$ as the $\mathrm{Cl}^{-}$salt and $\mathrm{NaCl} 5.0-5.5 \mathrm{mmol} / \mathrm{kg}$ per $\mathrm{d}$ was initiated to assure a normal or subnormal steady-state plasma total calcium concentration in a stable control period. After a 2-d prefeeding period and a 4-d control period, hypercalcemia was induced by increasing the rate of $\mathrm{CaCl}_{2}$ infusion and decreasing the rate of $\mathrm{NaCl}$ infusion for a $12-d$ period. In one dog the desired calcemic response required an increase in the calcium content of the intravenous infusion during the hypercalcemia period to levels greater than the corresponding sodium content in the control period. The synthetic diet was identical to that in groups I and II and was supplemented with $\mathrm{K}^{+} 2.0 \mathrm{meq} / \mathrm{kg}$ as the neutral phosphate and $\mathrm{NaHCO}_{3} 2.0 \mathrm{mmol} / \mathrm{kg}$ per $\mathrm{d}$.

\section{Studies in humans}

Group IV: effect of chronic hypercalcemic hyperparathyroidism induced by continuous PTH infusion in normal subjects $(n=4)$. The effect of chronic PTH infusion on calcitriol metabolism was evaluated in four normal human male volunteers (ages, 23-35 yr; weights, 68-79 kg). Each subject ingested a constant amount of a whole-food diet. ${ }^{2}$ All subjects ingested an identical amount of each dietary constituent per kilogram of body weight. Each subject received a dietary $\mathrm{NaCl}$ supplement $\left(1.49 \mathrm{mmol} / \mathrm{kg}\right.$ per d), raising the total $\mathrm{Na}^{+}$intake to $126.0 \mathrm{meq} /$ d per $70 \mathrm{~kg}$. At 8 a.m., heparinized arterialized venous blood samples from fasting subjects were obtained at 24-72-h intervals from a superficial hand vein. To assure a homogeneous blood sample source among species, blood samples were discarded if adequate arterialization $\left(\mathrm{PO}_{2}>65 \mathrm{mmHg}\right)$ was not achieved by hand warming. Urine was collected in 24-h pools in plastic bottles containing mineral oil and thymol-chloroform preservative. Values for urinary excretion and clearance data are reported as normalized to $70 \mathrm{~kg}$ body wt. The studies were approved by the Institutional Review Board, University of Florida, Gainsville, FL and informed consent was obtained from each subject.

Studies were initiated by instituting a 4-14 d prefeeding period in which the subjects equilibrated to the diet and other conditions of the protocol. During prefeeding and all subsequent periods of study each subject received a continuous intravenous infusion at a rate of 50 $\mathrm{ml} / 24 \mathrm{~h}(0.45 \% \mathrm{NaCl} / 1 \%$ human serum albumin $/ 0.01 \mathrm{~mol} /$ liter acetic acid) by means of a wearable pump (CorMed, Inc., Medina, NY). This infusion served as the vehicle for subsequent PTH administration. During a control period of 5-7 d duration, steady states of plasma

2. The diet composition, based on a 70.0-kg subject per $24 \mathrm{~h}$, is as follows: Calories, 2,660; N, $13.1 \mathrm{~g}$; fat, $63.6 \mathrm{~g}$; carbohydrate, $439.9 \mathrm{~g}$; $\mathrm{Na}^{+}, 21.7$ meq; $\mathrm{K}^{+}, 109.7$ meq; $\mathrm{Ca}^{++}, 37.3$ meq; $\mathrm{Mg}^{++}, 27.8 \mathrm{meq}$ phosphorus, $973 \mathrm{mg}$; and fluid, $3,539 \mathrm{ml}$. The daily diet was supplemented in each subject with three $\mathrm{CaCO}_{3}$ tablets (Eli Lilly \& Co., 650 $\mathrm{mg}$ ), raising the $\mathrm{Ca}^{++}$intake for a $70.0-\mathrm{kg}$ individual to 76.2 $\mathrm{meq} / 24 \mathrm{~h}$. 
calcium and phosphorus concentrations were achieved. After completion of control period observations, synthetic b-(1-34)-PTH $6,800 \mathrm{U} / \mathrm{mg}$ (Beckman Instruments, Inc., Fullerton, CA), was added to the infusate at a rate of $6 \mathrm{U} / \mathrm{kg}$ per $24 \mathrm{~h}$ for a period of $12-13 \mathrm{~d}$. The infusion rate was occasionally decreased when plasma calcium concentration exceeded $13 \mathrm{mg} / 100 \mathrm{ml}$ for $>24 \mathrm{~h}$. A 4-8-d recovery period followed the period of PTH administration in which PTH was removed from the infusate.

\section{Analytical procedures}

All determinations were performed in duplicate. Analytical methods used in this laboratory have been described in previous reports (17, 18). Plasma calcidiol (25-hydroxyvitamin $\mathrm{D}_{3}$ ) and calcitriol concentrations were measured as reported previously (21), with the exception that in the studies in humans, the calcitriol fraction from LH-20 chromatography was further chromatographed using a radial compression separation system (Waters Instruments, Inc., Rochester, MN) with an 8-mm Si radial compression column (particle size, $5 \mu \mathrm{m}$ ), a solvent system of isopropanol/hexane (8:92), and a flow rate of $4.5 \mathrm{ml} / \mathrm{min}$. Overall recoveries of initial tritiated calcidiol and calcitriol added to the plasma were $60-65$ and $60-70 \%$, respectively. Minimum assay detection limits for calcidiol and calcitriol are $\sim 5 \mathrm{ng} / \mathrm{ml}$ and $4 \mathrm{pg} / \mathrm{ml}$, respectively. Intraassay and interassay coefficients of variation for calcidiol (plasma concentration, $28 \mathrm{ng} / \mathrm{ml}$ ) are $\sim 10$ and $15 \%$, respectively, and for calcitriol (plasma concentration, $31 \mathrm{pg} / \mathrm{ml}$ ) are $\sim 12$ and $13 \%$, respectively. Plasma and urine calcium concentrations were determined by automated fluorometric titration (22), which measures nonchelated total calcium. Statistical analysis is by $t$ test (23).

\section{Results}

Group I: effect of chronic intravenous infusion of bPTH on mineral and vitamin $D$ metabolism in intact dogs. Chronic continuous administration of bPTH resulted in sustained hypercalcemia and hypophosphatemia (Fig. 1). No significant alterations in body weight or plasma protein concentration were observed. Plasma calcitriol concentration decreased from a stable control period value of $23 \pm 3$ to $14 \pm 3 \mathrm{pg} / \mathrm{ml}(P$ $<0.05$ ) (Table I).

In a single animal of group I, subsequent $\mathrm{Na}_{4}$ EGTAinduced normalization of PTH-induced hypercalcemia and hypophosphatemia resulted in an increase in plasma calcitriol level to approximately twice that observed in the control period. Subsequent substitution of $\mathrm{CaNa}_{2}$ EGTA (nonchelator) resulted in recurrence of hypercalcemia and resuppression of calcitriol concentration (Fig. 2). In two animals of group I, three periods of study were obtained with the following pooled

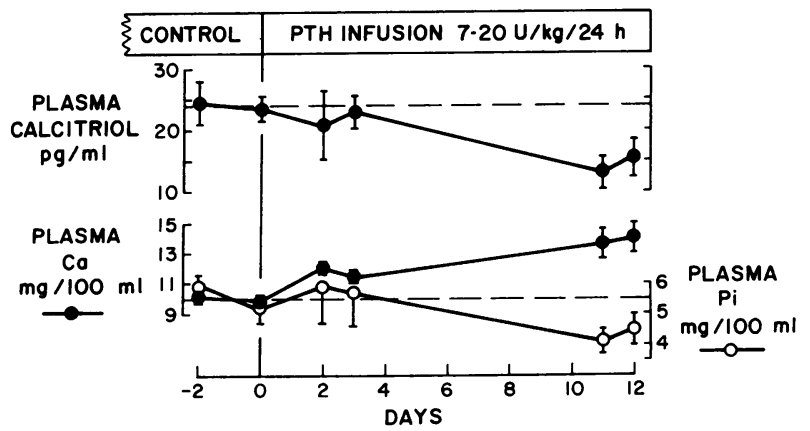

Figure 1. Effect of sustained continuous intravenous PTH infusion in intact dogs on plasma calcitriol, calcium, and phosphate concentrations (group I). values of plasma calcium and calcitriol concentration: control, 9.8 $\pm 0.2 \mathrm{mg} / 100 \mathrm{ml}, 21.8 \pm 1.4 \mathrm{pg} / \mathrm{ml}$; PTH (final $4 \mathrm{~d}$ ), 12.4 $\mathrm{mg} / 100 \mathrm{ml} \quad(P<0.001), \quad 10.6 \pm 0.9 \quad \mathrm{pg} / \mathrm{ml} \quad(P<0.001)$; PTH plus $\mathrm{Na}_{4}$ EGTA (final $3 \mathrm{~d}$ ), $8.9 \pm 0.4 \mathrm{mg} / 100 \mathrm{ml}$, $27.6 \pm 5.7 \mathrm{pg} / \mathrm{ml}$.

Group II: effect of chronic intravenous $\mathrm{Na}_{4}$ EGTA infusion in intact dogs. Chronic continuous administration of the calcium chelator, $\mathrm{Na}_{4}$ EGTA, resulted in sustained mild hypocalcemia and hyperphosphatemia. Plasma calcitriol concentration increased from a control value of $28 \pm 4$ to $41 \pm 8 \mathrm{pg} / \mathrm{ml}$ (Fig. 3).

Group III: effect of chronic hypercalcemia induced by the substitution of continuous intravenously administered calcium chloride for equivalent sodium chloride to TPTX dogs. Sustained infusion of calcium resulted in an increase in plasma calcium concentration from a chronic subnormal level to a sustained supernormal level (Table I, Fig. 4). Plasma phosphorus and calcitriol concentrations were not altered substantially.

Group IV: effect of chronic hypercalcemic hyperparathyroidism induced by continuous $P$ TH infusion in normal human subjects. Sustained infusion of bPTH (1-34) resulted in persistent hypercalcemia, hypophosphatemia, and decreased plasma calcitriol concentrations (Fig. 5). These results in human subjects were qualitatively similar to those in the normal dogs of group I. Plasma calcidiol concentration averaged $31 \pm 4$ $\mathrm{ng} / \mathrm{ml}$ during the control period and was not significantly different during days $7-13$ of PTH administration (30 $\pm 2 \mathrm{ng} /$ $\mathrm{ml})$. The ranges of normal human calcidiol and calcitriol concentrations in our laboratory are $15-60 \mathrm{ng} / \mathrm{ml}$ and $15-60$ $\mathrm{pg} / \mathrm{ml}$, respectively.

\section{Discussion}

Several lines of evidence might lead one to predict that the stimulatory effect of PTH on renal calcitriol production would result in a chronic increase in plasma calcitriol concentration in normal dogs and humans when experimentally induced PTH excess is permitted to persist into a steady-state period of secondary hypercalcemia and hypophosphatemia. First, the common clinical syndrome, primary hyperparathyroidism, is characterized by stable hypercalcemia, hypophosphatemia, and elevated plasma calcitriol concentration $(12,24-27)$. If persistent hypersecretion of PTH were the exclusive cause of the clinical syndrome, then elevated plasma calcitriol concentration should also obtain when PTH excess is of exogenous experimental origin. Second, hypoparathyroid rats exhibit deficient calcitriol production, which has been reported to be corrected by acute PTH administration, suggesting that PTH provides tonic stimulation of calcitriol levels $(3,9)$. Third, normal human subjects have been reported to respond with increased plasma calcitriol concentration after acute administration of large doses of PTH $(7,28)$. Fourth, direct addition of PTH to incubated rat renal slices resulted in large increases in calcitriol production (29). Fifth, direct addition of PTH to a renal mitochondrial preparation resulted in a dose-dependent increase in activity of the enzyme responsible for calcitriol production, 25-hydroxyvitamin D- $1 \alpha$-hydroxylase ( $1 \alpha$-hydroxylase) (10). However, since the pathogenesis of human primary hyperparathyroidism is not established as caused by altered production of a single hormone, 


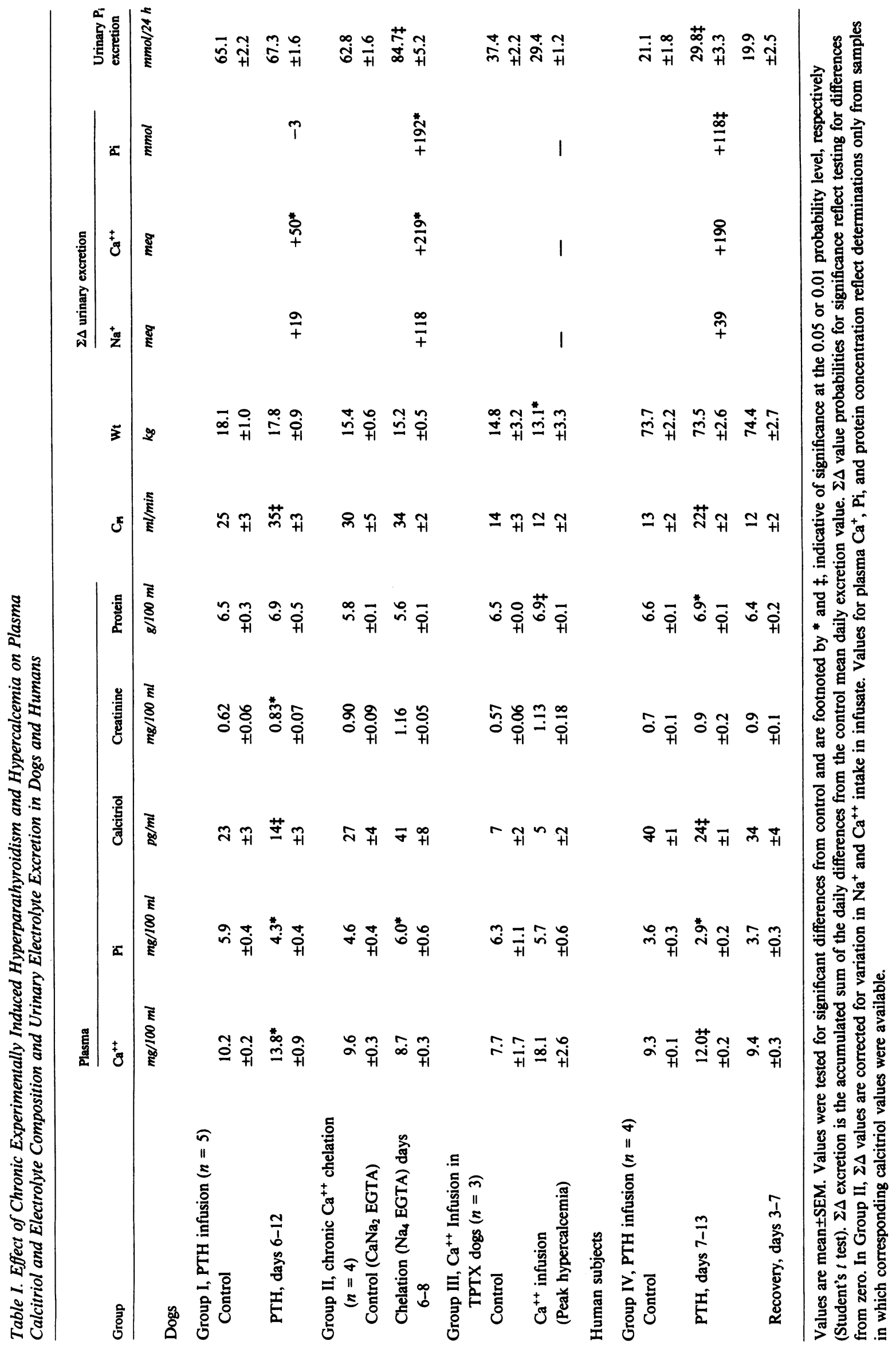




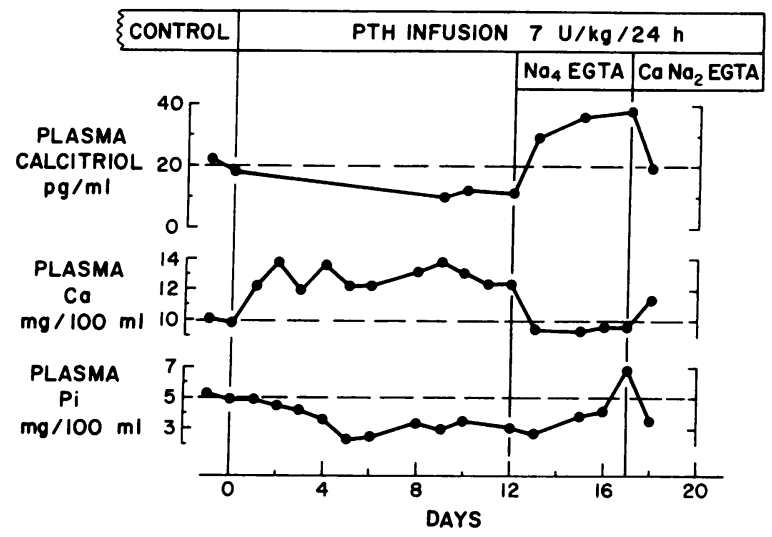

Figure 2. An animal from group I: effect of chelator ( $\mathrm{Na}_{4}$ EGTA)induced normalization of plasma calcium concentration on PTHinduced suppression of calcitriol levels. The period of chelation was followed by recovery to hypercalcemia induced by infusion of prechelated EGTA ( $\mathrm{CaNa}_{2}$ EGTA).

and since vitamin $\mathrm{D}$ metabolism has not been investigated previously in experimentally induced states of chronic PTH excess, the present results revealing decreased calcitriol concentration in experimental exogenous PTH excess (groups I and IV) do not necessarily conflict with these predictions.

It is possible that plasma phosphorus concentration provides the critical control of plasma calcitriol concentration in states of chronic PTH excess. Hypophosphatemia/phosphate depletion or increased renal phosphate clearance are nearly invariable components of human primary hyperparathyroidism and are thereby associated with increased plasma calcitriol concentration (12, 24-27). Moreover, long-term provision of a dietary phosphorus supplement to patients with primary hyperparathyroidism has been reported to decrease elevated calcitriol concentration to normal values despite a phosphorus-induced increase in serum immunoreactive PTH concentration (25). This finding is consistent with recent reports in adult human subjects (15) and children with renal insufficiency (14) that chronic dietary phosphorus restriction can increase and phosphate loading can decrease steady-state plasma calcitriol concentration. The present findings of sustained decreases in plasma calcitriol concen-

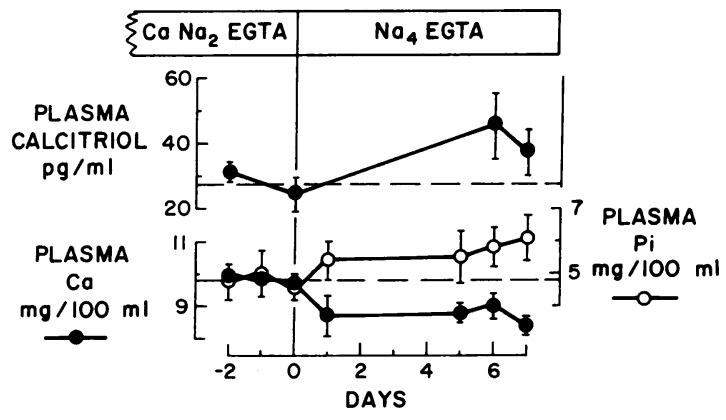

Figure 3. Effect of chronic hypocalcemic hyperparathyroidism induced by continuous $\mathrm{Na}_{4}$ EGTA administration on plasma calcitriol, calcium, and phosphorus concentrations (group II).

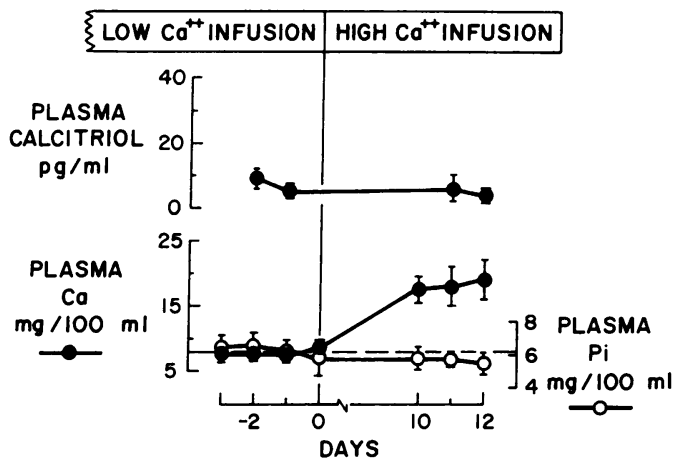

Figure 4. Effect of sustained high-dose calcium infusion on plasma calcitriol, calcium, and phosphorus concentrations in TPTX dogs (group III).

tration despite hypophosphatemia during experimentally induced continuous PTH infusion in both humans and dogs, provide evidence that the hypophosphatemia associated with a primary and sustained PTH excess state is not the major determinant of circulating calcitriol levels (groups I and IV). Moreover, the present finding of an increased calcitriol concentration during experimentally induced chronic secondary hyperparathyroidism in association with sustained hyperphosphatemia (see below) is further evidence against a dominant role for phosphate homeostasis per se in determining calcitriol levels in conditions of long-term hyperparathyroidism. The present studies thus show that the established effects of PTH and phosphorus on vitamin D metabolism are insufficient to explain the sustained decreased plasma calcitriol concentration

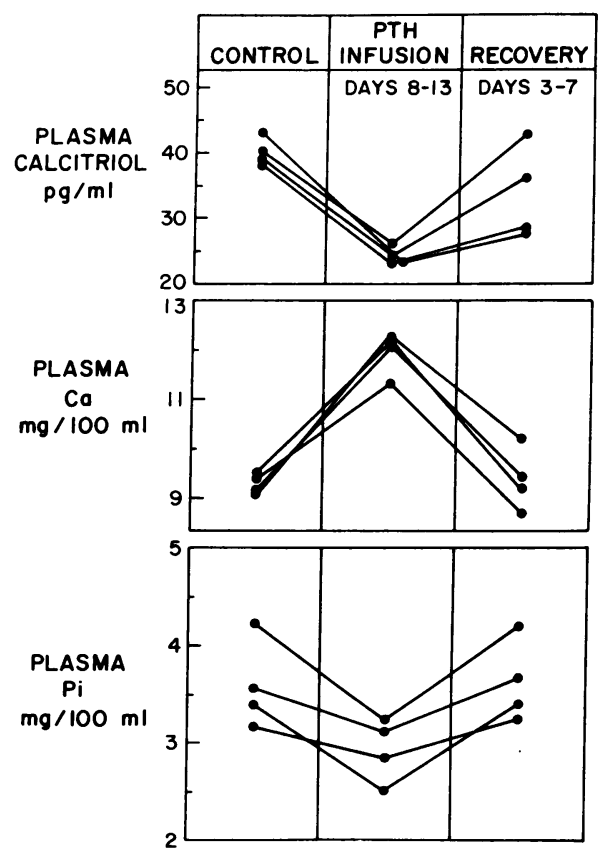

Figure 5. Effect of chronic continuous PTH infusion in normal human subjects on plasma calcitriol $(P<0.01)$, calcium $(P<0.01)$, and phosphorus concentrations $(P<0.05)$ (group IV). 
in models of primary PTH excess (high PTH, hypophosphatemia; groups I and IV) and increased calcitriol concentration in a model of secondary PTH excess (high PTH, hyperphosphatemia; group II).

The occurrence of hyperphosphatemia despite augmented renal phosphate clearance in the group with secondary hyperparathyroidism (group II) is of interest inasmuch as an augmentation of renal phosphate clearance also accompanied the development of hypercalcemic hypophosphatemic hyperparathyroidism (groups I and IV). The observation that urinary phosphate excretion remained persistently and greatly elevated above control levels during the steady state of EGTA-induced hypocalcemia is consistent with the thesis that gastrointestinal phosphate absorption increased (or failed to decrease) only in animals with secondary PTH excess owing to increased circulating calcitriol levels (1). The cumulative increment in phosphate excretion of $9.6 \mathrm{mmol} / \mathrm{kg}$ in group II hypocalcemic dogs is markedly greater than the values of $0 \mathrm{mmol} / \mathrm{kg}$ and 1.7 $\mathrm{mmol} / \mathrm{kg}$ in groups I and IV hypercalcemic dogs and humans (Table I). Taken together with the finding that the cumulative increment in urinary calcium excretion followed a similar pattern $(11.0 \mathrm{meq} / \mathrm{kg}$, group II vs. 1.0 and $0.6 \mathrm{meq} / \mathrm{kg}$ in groups I and IV), the occurrence of persistent hyperphosphatemia and hyperphosphaturia in dogs with secondary hyperparathyroidism supports the possibility that augmented calcitriol levels in this condition (but not in models of primary PTH excess) resulted in a large increase in the systemic loads of both calcium and phosphate requiring renal excretion. Since the equimolar EGTA salts infused in both control and experimental periods (group II) obligate identical calcium loads requiring renal excretion, the large increment in urinary calcium excretion is not attributable to chelator infusion, per se. Since both the models of primary PTH excess and secondary PTH excess employed herein would be expected to exhibit large losses of bone calcium and phosphate to ECF, the striking differences between primary and secondary models with respect to the observed magnitude of sustained urinary calcium and phosphate losses, suggest a calcitriol-mediated alteration in gastrointestinal absorption of both ions (1).

The potential role of chronic changes in plasma calcium concentration in determining the direction and magnitude of the response of plasma calcitriol concentration to sustained PTH excess requires consideration. It is established that chronic oral calcium loading in humans results in decreased plasma calcitriol concentration and that chronic calcium restriction results in increased plasma calcitriol concentration (5). However, these results have been interpreted as suggesting an effect of secondarily decreased or increased PTH levels rather than direct effects of small but undetectable changes in plasma calcium concentration. More recently, however, Trechsel et al. (3) have shown in rats that chronic calcium restriction resulted in increased plasma calcitriol concentration even in TPTX rats or rats with a fixed PTH supply as well as in control rats. The operation of plasma calcium concentration as the dominant mechanism in calcitriol metabolism was not established by these studies, however, since as in the human studies, differences in plasma calcium concentration were not demonstrable consistently in response to the dietary maneuver. In studies reported by Hughes et al. (4), however, TPTX rats were provided a calcium-restricted diet for a longer period of time ( 2 wk) to achieve appreciable hypocalcemia, and an increase in calcitriol concentration was observed despite hyperphosphatemia. Nevertheless, both normocalcemic and hypocalcemic TPTX groups' calcitriol levels were very low (as reported herein [group III] and in other reports in TPTX animals [3-9]), and Hughes et al. concluded that calciumdependent control of calcitriol metabolism is mediated largely by secondary changes in PTH secretion. This interpretation is consistent with enzyme assay data reported in intact chicks fed diets varying in calcium and phosphorus content to provide wide variation in plasma calcium concentration confined to the normal and hypocalcemic range: $1 \alpha$-hydroxylase activity correlated inversely with plasma calcium concentration (8).

The results of studies evaluating the specific (PTH-independent) role of acute changes in ECF calcium concentration on calcitriol production utilizing isolated chick renal tubules bathed in a Krebs-Ringer solution are consistent with an effect of hypercalcemia to decrease calcitriol production but inconsistent with an effect of hypocalcemia to stimulate calcitriol production (30). The studies in incubated tubules revealed a biphasic response of calcitriol production to increasing ambient calcium concentration. At subphysiologic levels $(<0.5 \mathrm{mM})$, calcitriol production was inhibited, whereas at normal or superphysiological levels $(>1.0 \mathrm{mM})$, increasing calcium concentration also inhibited production relative to maximal rates observed in the $0.5-1.0 \mathrm{mM}$ range (30). A preliminary report using incubated rat renal slices has confirmed that an increase in medium calcium concentration from 0.5 to $1.25 \mathrm{mM}$ resulted in decreased calcitriol production (31). Numerous investigations of the effects of incubation medium calcium concentration on renal mitochondrial calcitriol production have been reported. A comprehensive and critical review of these reports has been published (2), which points out the methodological difficulties encumbering interpretation of the conflicting results. Based on current information it is difficult to predict whether changes in ECF calcium concentration might modulate mitochondrial calcitriol production through direct effects on cytosolic calcium concentration or through unknown mechanisms.

Whereas no previous investigations of the chronic plasma calcitriol response to experimentally induced hypocalcemic or hypercalcemic hyperparathyroidism have been reported, Hove et al. (16) reported recently that a 34-h infusion of PTH to three normal calves resulted in decreased plasma calcitriol concentration as hypercalcemia developed. Whether a persistent suppression of calcitriol concentration would have occurred if a steady-state of vitamin D and mineral homeostasis had been permitted to develop was not investigated. Additional studies by Hove et al. (16) in two goats receiving a constant superphysiological infusion rate of PTH, showed that superimposed hypercalcemia resulting from a brief calcium infusion was associated with a decreased plasma calcitriol concentration. The reason(s) for the opposite results of acute PTH administration to humans (increased calcitriol concentration; 7,28 ) were not elucidated by these investigations. The potential role of plasma calcium-mediated modulation of calcitonin metabolism in mediating the present changes in calcitriol metabolism as well as the acute changes reported by Hove et al. remains to be determined $(32,33)$.

The finding of the present studies that sustained hypercal- 
cemia induced in aparathyroid dogs (group III) resulted in only a minimal trend toward a reduction in plasma calcitriol concentration, raises the possibility that plasma calcium concentration modulates circulating calcitriol levels only in the presence of PTH. Alternatively, since the hypercalcemic calcitriol levels in this group $(5 \mathrm{pg} / \mathrm{ml})$ are at the detection limit of current assay techniques $(4 \mathrm{pg} / \mathrm{ml})$, it might be argued that PTH-independent suppression of plasma calcitriol concentration would be unlikely to be detected when basal levels are near the detection limit $(7 \mathrm{pg} / \mathrm{ml})$ owing to the aparathyroid state.

The present results provide strong evidence in both humans and dogs that during experimental states of chronic PTH excess, alterations in plasma calcium concentration dictate the directional response of plasma calcitriol concentration. These studies further indicate that the long-term potency of plasma calcium concentration as a regulator of plasma calcitriol concentration is sufficient to override opposing modulation by plasma phosphorus concentration and experimentally induced hyperparathyroidism in both dogs and humans. The reason(s) for the important differences in the present findings from those of primary hyperparathyroidism were not elucidated by the present studies. Further investigations into the proximate cause of the clinical syndrome (e.g., hypersecretion of additional hormones) as well as investigation of more prolonged experimental models than those reported herein will be of great value in approaching this question.

\section{Acknowledgments}

We thank Sandra Mackie, Leon Ilnicki, and R. Malcolm Privette for technical assistance.

These experiments were supported by grants AM-31626, AM34860 , and RR-00082 from the National Institutes of Health, U. S. Public Health Service, and grants from the Research Service, Veterans Administration.

\section{References}

1. DeLuca, H. F. 1978. Vitamin D metabolism and function. Arch. Intern. Med. 138:836-847.

2. Fraser, D. R. 1980. Regulation of the metabolism of vitamin D. Physiol. Rev. 60:551-613.

3. Trechsel, U., J. A. Eisman, J. A. Fischer, J.-P. Bonjour, and H. Fleisch. 1980. Calcium-dependent, parathyroid hormone-independent regulation of 1,25-dihydroxyvitamin D. Am. J. Physiol. 239:E119E124.

4. Hughes, M. R., P. F. Brumbaugh, M. R. Haussler, J. E. Wergedal, and D. J. Baylink. 1975. Regulation of serum $1 \alpha, 25-$ dihydroxyvitamin $D_{3}$ by calcium and phosphate in the rat. Science (Wash. DC). 190:578-580.

5. Adams, N. D., R. W. Gray, and J. Lemann, Jr. 1979. The effects of oral $\mathrm{CaCO}_{3}$ loading and dietary calcium deprivation on plasma 1,25-dihydroxyvitamin D concentrations in healthy adults. $J$. Clin. Endocrinol. Metab. 48:1008-1016.

6. Ribovich, M. L., and H. F. DeLuca. 1978. Effect of dietary calcium and phosphorus on intestinal calcium absorption and vitamin D metabolism. Arch. Biochem. Biophys. 188:145-156.

7. Eisman, J. A., J. D. Wark, R. L. Prince, and J. M. Moseley. 1979. Modulation of plasma 1,25-dihydroxyvitamin $\mathrm{D}$ in man by stimulation and suppression tests. Lancet. II:931-933.
8. Henry, H. L., R. J. Midgett, and A. W. Norman. 1974. Regulation of 25-hydroxyvitamin $\mathrm{D}_{3}$-1-hydroxylase in vivo. J. Biol. Chem. 249:7584-7592.

9. Garabedian, M., M. F. Holick, H. F. DeLuca, and L. T. Boyle. 1972. Control of 25 -hydroxycholecalciferol metabolism by parathyroid glands. Proc. Natl. Acad. Sci. USA. 69:1673-1676.

10. Kremer, R., and D. Goltzman. 1982. Parathyroid hormone stimulates mammalian renal 25-hydroxyvitamin $\mathrm{D}_{3}$-1 $\alpha$-hydroxylase in vitro. Endocrinology. 110:294-296.

11. Aarskog, D., and L. Aksnes. 1980. Acute response of plasma 1,25-dihydroxyvitamin D to parathyroid hormone. Lancet. I:362-363.

12. Gray, R. W., D. R. Wilz, A. E. Caldas, and J. Lemann, Jr. 1977. The importance of phosphate in regulating plasma $1,25-(\mathrm{OH})_{2}-$ vitamin $\mathrm{D}$ levels in humans: studies in healthy subjects, in calcium stone formers and in patients with primary hyperparathyroidism. $J$. Clin. Endocrinol. Metab. 45:299-306.

13. Rader, J. I., D. J. Baylink, M. R. Hughes, E. S. Safilian, and M. R. Haussler. 1979. Calcium and phosphorus deficiency in rats: effects on PTH and 1,25-dihydroxyvitamin $\mathrm{D}_{3}$. Am. J. Physiol. 236: E118-E122.

14. Portale, A. A., B. E. Booth, B. P. Halloran, and R. C. Morris, Jr. 1984. Effect of dietary phosphorus on circulating concentrations of 1,25-dihydroxyvitamin $\mathrm{D}$ and immunoreactive parathyroid hormone in children with moderate renal insufficiency. J. Clin. Invest. 73:15801589.

15. Portale, A. A., B. P. Halloran, M. M. Murphy, and R. C. Morris, Jr. 1984. Dietary phosphorus can determine the serum concentration of $1,25-(\mathrm{OH})_{2} \mathrm{D}$ by determining its production rate in humans. Clin. Res. 32:405.

16. Hove, K., R. L. Horst, E. T. Littledike, and D. C. Beitz. 1984. Infusions of parathyroid hormone in ruminants: hypercalcemia and reduced plasma 1,25-dihydroxyvitamin D concentrations. Endocrinology. 114:897-903.

17. Hulter, H. N., L. P. Ilnicki, J. A. Harbottle, and A. Sebastian. 1977. Impaired renal $\mathrm{H}^{+}$secretion and $\mathrm{NH}_{3}$ production in mineralocorticoid-deficient glucocorticoid-replete dogs. Am. J. Physiol. 232: F136-F146.

18. Hulter, H. N., J. H. Licht, R. D. Glynn, and A. Sebastian. 1979. Renal acidosis in mineralocorticoid deficiency is not dependent on $\mathrm{NaCl}$ depletion or hyperkalemia. Am. J. Physiol. 236:F283-F294.

19. Fox, J., and H. Heath III. 1981. The "calcium clamp": effect of constant hypocalcemia on parathyroid hormone secretion. Am. J. Physiol. 240:E649-E655.

20. Hulter, H. N., L. E. Gustafson, E. L. Bonner, Jr., R. D. Toto, and S. Mackie. 1984. Thyroid replacement in thyroparathyroidectomized dogs. Miner. Electrolyte Metab. 10:228-232.

21. Halloran, B. P., P. Schaefer, M. Lifschitz, M. Levens, and R. S. Goldsmith. 1984. Plasma vitamin D metabolite concentrations in chronic renal failure: effect of oral administration of 25-hydroxyvitamin $D_{3}$. J. Clin. Endocrinol. Metab. 59:1063-1069.

22. Alexander, R. L., Jr. 1971. Evaluation of an automatic calcium titrator. Clin. Chem. 17:1171-1175.

23. Snedecor, G. W., and W. G. Cochran. 1967. Statistical methods. Iowa State University Press, Ames, IA. Sixth ed. 580 pp.

24. Broadus, A. E., R. L. Horst, R. Lang, E. T. Littledike, and H. Rasmussen. 1980. The importance of circulating 1,25-dihydroxyvitamin $\mathrm{D}$ in the pathogenesis of hypercalciuria and renal stone formation in primary hyperparathyroidism. N. Engl. J. Med. 302:421-426.

25. Broadus, A. E., J. S. Magee, L. E. Mallette, J. M. Gertner, and R. Baron. 1983. A detailed evaluation of oral phosphate therapy in selected patients with primary hyperparathyroidism. J. Clin. Endocrinol. Metab. 56:953-961.

26. Lund, B., O. H. Sorensen, B. Lund, J. E. Bishop, and A. W. Norman. 1980. Stimulation of 1,25-dihydroxyvitamin D production 
by parathyroid hormone and hypocalcemia in man. J. Clin. Endocrinol. Metab. 50:480-484.

27. Maierhofer, W. J., R. W. Gray, N. D. Adams, G. A. Smith, and J. Lemann, Jr. 1981. Synthesis and metabolic clearance of 1,25dihydroxyvitamin $\mathrm{D}$ as determinants of serum concentrations: a comparison of two methods. J. Clin. Endocrinol. Metab. 53:472-475.

28. Aksnes, L., and D. Aarskog. 1980. Effect of parathyroid hormone on 1,25-dihydroxyvitamin D formation in Type I pseudohypoparathyroidism. J. Clin. Endocrinol. Metab. 51:1223-1226.

29. Armbrecht, H. J., N. Wongsurawat, T. V, Zenser, and B. B. Davis. 1984. Effect of PTH and $1,25(\mathrm{OH})_{2} \mathrm{D}_{3}$ on renal $25(\mathrm{OH}) \mathrm{D}_{3}$ metabolism, adenylate cyclase, and protein kinase. Am. J. Physiol. 246:E102-E107.

30. Bikle, D. D., and H. Rasmussen. 1975. The ionic control of 1,25-dihydroxyvitamin $D_{3}$ production in isolated chick renal tubules. J. Clin. Invest. 55:292-298.

31. Armbrecht, H. J., N. Wongsurawat, T. V. Zenser, and B. B. Davis. 1983. In vitro modulation of renal 25-hydroxyvitamin $D_{3}$ metabolism by 1,25-(OH $)_{2} \mathrm{D}_{3}$ and calcium. Kidney Int. 23:94. (Abstr.).

32. Kawashima, H., S. Torikai, and K. Kurokawa. 1981. Calcitonin selectively stimulates 25 -hydroxyvitamin $\mathrm{D}_{3}-1 \alpha$-hydroxylase in proximal tubule of rat kidney. Nature (Lond.). 291:327-329.

33. Emmertsen, K., F. Melsen, L. Mosekilde, B. I. Lund, B. J. Lund, O. H. Sorensen, H. E. Nielsen, H. Solling, and H. H. Hansen. 1981. Altered vitamin D metabolism and bone remodeling in patients with medullary thyroid carcinoma and hypercalcitoninemia. Metab. Bone Dis. and Relat. Res. 4:17-23. 